\title{
Teacher Interns' Conquering the Barriers in a New Mode of Teaching
}

\author{
Fabiana P. Peñeda ${ }^{1}$, Maria Lourdes G. Tan ${ }^{2}$, Thea A. Ticoy ${ }^{3 *}$ \\ Ifabiana.peneda@lnu.edu.ph \\ ${ }^{1}$ College of Education, Leyte Normal University, Tacloban City, 6500, Philippines \\ ${ }^{2}$ marialourdes711@lnu.edu.ph \\ ${ }^{2}$ College of Education, Leyte Normal University, Tacloban City, 6500, Philippines \\ 3 thea.ticoy@lnu.edu.ph \\ ${ }^{3}$ College of Education, Leyte Normal University, Tacloban City, 6500, Philippines
}

\begin{abstract}
A teacher internship is an opportunity to nurture future teachers. This study aimed to identify teacher interns' challenges and coping strategies using blended learning modalities in the new normal. Participants of the study were ten (10) teacher interns who were purposely selected. Data were collected through a semi-structured questionnaire in the google form and virtual focus-grouped discussion using Colaizzi's data analysis method. Results revealed the following challenges: unstable internet connectivity, strenuous virtual class management, virtual class distractions, insufficient online teaching mastery and financial shortcomings. Coping strategies include: strong personal disposition and reaching out others for help. Teacher interns suggested having an easy online tracing of the students' performance in an online system, virtual teaching growth, and stable internet connectivity to deliver lessons effectively.
\end{abstract}

Keywords: Teacher interns; barriers; blended learning; phenomenology

\section{Introduction}

It is the utmost goal of education to produce quality teachers in the field through teacher interns' adequate training in blended learning. The sudden occurrence of Covid-19 suddenly gives a tremendous challenge to educators, especially the private and public schools. The continued rising of pandemic patients affects all education sectors in the world (UNESCO, 2020). In the study of Crawford et al. (2020) explained that learners and educators tend to continue their schooling using blended learning through online learning modalities printed learning modality called "Blended Learning." The scenario allows the academes to formulate a new teaching style to cater to the unusual learning set-up.

The blended learning modality helps teacher interns to be more creative and resourceful despite the inadequate training in the pedagogical approaches used in their online teaching. They tend to seek others' help, particularly in using laptops and internet connection so they can deliver well their lessons on time. The study's end goal is to determine the experiences of teacher interns, challenges encountered, how they deal with the current situation, and suggestions based on their experiences. This study can help the primary education faculty and institution to generate a more realistic and robust personality of teacher interns. This research helps educators provide essential online teaching training to have a strong foundation on the strategies and approaches they will use in this type of learning modality. Furthermore, this study prepares the teacher interns to cope with challenges and improve their performance in using blended learning in the new normal since at this time of Covid pandemic no particular study about teacher interns' experiences is made exclusively in the region. 


\section{Theoretical framework}

This research study is anchored in Dewey's theory of experiences and Kolb's experiential learning theory.

Dewey defined the theory of experience as the connection between individual learning experiences, behavior, and future decisions (Dewey, 1986). The concept involves interaction with students and the environment in order for the individual to be influential in his way. This theory relates to the study because it provides an overview of teacher interns' experiences during online teaching to the new normal of learning. During their internship, the blended learning modality allows them to be creative in dealing with their challenges. Despite experiencing slow internet connections, they allow themselves to be optimistic. They did not give up easily since they possess a strong personality and belong to a support system by providing them with the necessary things helpful in their online teaching.

Likewise, Kolb defines the theory of experiential learning as to how an individual acquires knowledge from the experience of understanding and incorporating it into their experience (Kolb, 1984). The theory shows how teacher interns selected technology and materials suitable for online teaching experiences. This theory also allows teacher interns to acquire their actual teaching knowledge. This helps them gained the methodologies through their experiences on how to execute and manage online lessons.

\section{Review of literature}

The disease outbreak has embraced a delicate task to achieve learning through alternative education to adapt to this current situation (Bonk et al., 2016). The Department of Education (DepEd) adopted multiple learning modalities, which include: online learning modalities, modular learning modalities, or both called blended learning modalities (Tuscano, 2020). Blended learning offered several challenges not only to teachers but to teacher interns as well. As mentioned in the study of (Agung et al., 2020), limited internet connection affects teacher interns' performance in online teaching. Alimi (2018) further explained that unstable internet connectivity could affect the progress in simulation of teaching, tutoring, and class management. McGarr (2020) admitted that when the teacher interns could not regulate the student's attitude online, it affects learning. According to Rufai et al. (2015) view difficulty in classroom management to reduce learning of students. The statement is being supported wherein virtual distractions in learning include $89 \%$ of the students who are not attentive in the online class (McCoy, 2016). Also, lack of teaching mastery online prompts the teacher interns to implement strategies and appropriate online teaching methods (Palloff \& Pratt, 2013). Lack of skills using and assessing teaching materials and tools for online teaching can affect an individual's behavior towards the lesson's delivery (Elibariki, 2017).

Technology tool familiarity helps the teacher interns face the problems in the new mode of teaching. Technology literacy would bring changes to the teaching and learning process organization at all levels (Jung \& Latchem, 2011). Using technology increases student engagement, wherein teachers and learners can interact with other people in different institutions across the globe. Open communication and constant follow up with students is the key when it gets complicated. Similarly, reaching out to students goes to the school faculty and personnel (Dhawan, 2020).

Providing support through collaborative and project-based learning makes distance learning engaging and motivating (Bonk et al., 2016). Baloran \& Hernan (2020) suggested that teachers should be trained to improve class management skills and resiliency practices to effectively face unexpected school crises. They added that school leaders must motivate teachers to reduce their uncertainties through cognitive psychological interventions and engage actively in school activities. Moreover, schools must prioritize and ensure teachers' health and safety. 
Training on virtual teaching, conferences, and several innovations reduce digital illiteracy (Bailey \& Schurz, 2020).

\section{Research Questions}

This research's objectives were to identify the difficulties, coping mechanisms, and teacher interns' recommendations using online, blended learning. It aimed explicitly to address the following research questions;

1. What are the challenges encountered by teacher interns using the blended modality of learning?

2. What are the coping mechanisms of teacher interns with the challenges encountered in the blended modality of learning?

3. What are the teacher interns' suggestions to improve teaching using the blended modality of learning?

\section{Methodology}

\subsection{Research Design}

This study used the descriptive phenomenological method to explore the challenges, coping mechanisms, and suggestions of teacher interns in responding to the challenges using blended learning modalities during the new normal.

\subsection{Research Locale}

The researchers administered the study in one of the universities in Leyte, Philippines. The university's primary aim is to produce globally competitive educators, empowered, and imbued with Filipinos high ideals, aspirations, and traditions. It aims to provide preservice training through supervised clinical and field-based practice experience and provide an appropriate and enriched curriculum for teacher education. Further, teacher interns' exposure to test innovations and other alternative modes of teaching delivery, conduct research, and use results to provide participation in community extension services.

\subsection{Research Participants}

The research participants were the Basic Elementary teacher interns deployed for the School Year 2019 - 2020 in the university's laboratory school. Researchers chose them through purposive sampling, where the researchers based their judgment when selecting the participants in terms of their shared subject major field (Creswell \& Plano Clark, 2011).

\section{4 Research Instrument and Data Collection}

The instrument utilized for the study was a survey questionnaire through google form validated by experts. The survey questionnaire was composed of questions on the challenges encountered, coping mechanisms, and suggestions to improve teaching in the blended modality of learning. It also includes recorded virtual focus group discussions of the teacher interns during the new normal. The questionnaire is the most suitable instrument because it helps the researcher gather information from a group with various backgrounds. The results remain anonymous, save time, and be presented in a paper format, and there is little risk of prejudice (Kothari, 2004).

\subsection{Data Gathering Procedure}

Data gathered from the participant were done through google meet using survey questionnaires in google forms and focus group discussion. After the online survey, the researchers were guided common-sense rules on disengagement by Lofland's (1990), which include: 1) Avoiding leaving abruptly; 2) Saying goodbye personally; 3) Promising to keep in touch, and 4) Keeping in touch as a situation dictated (De La Cruz, 2020). Researchers also 
conducted the validity check by having a follow-up online interview in the participants' date and time.

\subsection{Data Analysis}

This study employed Collaizi's phenomenological method of data analysis. Shosha (2012) explained the following Collaizi's steps: 1). each transcript is real and reveals to get the whole concept of the content, 2). getting significant statements for the transcribe, 3). formulate meaning for these meaningful statements, 4). the developed meaning was classified, and clusters of themes, 5). integrate findings of the study into a detailed description, 6). describing the phenomenon of the study, and 7). validity findings with the experiences of participants.

\section{Results and Discussion}

A single case descriptive analysis was used in data collection. Researchers created some themes to recognize teacher interns' challenges, coping strategies, and suggestions in blended learning modalities. Based on their interpretations, many themes were classified. The following themes were identified:

\section{Preservice teachers' challenges encountered in Blended Learning Modality}

Theme 1: Unstable Internet Connectivity

Nowadays, many schools are influenced by the sudden change in styles in the execution of teaching. The blended learning approach utilizes synchronous and asynchronous instruction delivery involving instructors, preservice teachers, and students (Allayyar et al., 2012). Of these teaching styles, the most affected are preservice teachers, who have deficient internet access, which can cause them to postpone their scheduled teaching delivery. Tsitsia et al. (2020) agreed that one of the factors influencing online learning experiences is internet unreliable access.

Significant response 1: "The challenges that I encountered are: poor internet connection, making new approaches, using the computer, distance classroom management, lack of student motivation."

Significant response 2: "Poor internet connection, unnecessary noise, hard times in seeing all my students during our class, having difficulties in trying to discipline my students through online, can't do the checking of attendance."

Significant response 3: "Internet connectivity, distance classroom management, delivery of the discussion, passing the output in times that there were no internet connection, sources in making it instructional materials."

Theme 2: Strenuous Virtual Classroom Management

Disciplining students in face-to-face teaching is a big challenge that preservice teachers need to resolve during their training (Vonderwell \& Turner, 2005). More so, preservice teachers need to maintain students' presence and active participation during the virtual classroom. The interactive virtual classroom is a challenging task to be met by every preservice teacher during their online teaching since they cannot detect if students are physically present, particularly those who have mute microphones and off cameras. The virtual classroom encourages learners to be more participatory, informed, and provide an engaging learning atmosphere, not merely for delivering learning materials (Rufai et al., 2015) in which preservice teachers should be observed.

Significant response 1: "Poor internet connection, unnecessary noise, hard times in seeing all my students during our class, having difficulties in trying to discipline my students through online, can't do the checking of attendance".

Significant response 2: "The challenges I've encountered in using blended learning during my internship are the following: technical issues, distractions, time management, 
lack of in-person interaction and the problem of managing and assessing learners progress".

Significant response 3: "How to handle classroom management online".

\section{Theme 3: Virtual Class Distractions}

The Philippines is presently adapting to online learning, yet there are many points to consider in this kind of online teaching, particularly disruptions that involve unwanted noise from the environment, undisciplined students' behavior, and unannounced power interruption (Bartholomew, 2018). These simulated class distractions often have to be met, aside from planning their learning resources. Thus, virtual online disruptions will stress the preservice teachers' success, as they cannot focus on their other teaching assignments.

Significant response 1: "Laptop to use, poor internet connection, no quiet place for my online teaching, low budget for load."

Significant response 2: "Poor internet connection, unnecessary noise, hard times in seeing all my students during our class, having difficulties in trying to discipline my students through online, can't do the checking of attendance".

Significant response 3: "Slow internet connection, power interruption, first time to teach online".

Theme 4: Insufficient online teaching mastery

The lack of online mastery of teaching can reduce trust in teaching. To effectively deliver online teachings, teacher interns need to have strong foundations about the online pedagogical methods and approaches. Experiencing the various strategies for online teaching can assist future educators to be very diverse in online teaching.

Significant response 1: "Poor connection, lack of time, learning materials and technology to be used in online teaching, financial problem and not familiar with some online application that can be used in teaching online".

Significant response 2: "Slow internet connection, power interruption, first time to teach online".

Theme 5: Financial shortcomings

Many educators, especially preservice teachers, are struck with this kind of need to embrace the virtual world education. Some of them cannot afford a gadget to do their schoolwork, and others do not have a sufficient budget to purchase load data. Financial shortage is one of the obstacles in the blended learning modality faced by preservice teachers (Owston et al., 2008).

Significant response 1: "No Laptop to use, poor internet connection, quiet place for my online teaching, low budget for load".

Significant response 2: "Poor connection, lack of time, learning materials and technology to be used in online teaching, financial problem and not familiar with some online application that can be used in teaching online".

\section{Preservice teachers' coping mechanisms in Blended Learning Modality}

Theme 1: Strong personal disposition

Knowing a vigorous personality will lead to the right individual, and once they face challenges, they can think about a different way of overcoming them. As Covid-19 entered the school year in which preservice teachers conducted their practicum, they learned to have a definite inclination and judgment, especially in this form of modality where they were so inexperienced (McAfee, 2018). In this kind of simulated instruction, preservice teachers have an abrupt encounter in which self-adjustment brought resourcefulness, allowing them to do their research on this new teaching method (Davis, 2018).

Significant response 1: "Setting a right mindset towards distance education - it helped me a lot in adjusting and coping in this new normal." 
Significant response 2: "I became calm, patient in everything I did, I studied hard and searched for what I could not understand so that I could overcome all the challenges I encountered.

Significant response 3: "Adapting and being flexible was my way of overcoming the challenges in this new normal way of teaching."

Theme 2: Reaching out for others

The community allows people to address the problems they encountered. It is acceptable to ask someone else for help, particularly in terms of guidance and economic assistance (Rickwood et al., 2005). Members of the preservice teachers' family are the prominent people who can provide an individual financially and morally. In addition, their acquaintances and those they trust can also be asked for assistance in this time of the pandemic (Alvis et al., 2020). Specifically, when the preservice teachers do everything, and nothing happens, it is good to express oneself.

Significant response: "I just find ways to go to my friends who have strong internet connection, seek their ideas, and adjust the new normal environment of teaching."

Significant response: "I make another way to overcome those challenges like for example in my first day of online teaching, I had no laptop to use, so I go to school every time I teach. I had to change because, with my sister's help, she borrowed a netbook from her friend and gave me pocket Wi-Fi."

\section{Preservice teachers' suggestions in Blended Learning Modality}

Theme 1: Easy online tracking of students' performance

One advice from the preservice teachers is to provide accurate monitoring of the pupils' learning output to have more accessibility to their academic performance. A single mechanism for rapid identification needs to be established by the school, where learners can easily recognize and access their school forms (Hill \& Hannafin, 2001). Additionally, monitoring learners' progress through the learning system can allow them to see students' outputs in a specific subject so that teachers can give a particular intervention.

Significant response 1: "Keep on update - always update your student what is going to on because most of time some students had some poor internet connection".

Significant response 2: "Get some reports about your learners - you always monitor the students to see they are excelling and where they are struggling".

Theme 2: Virtual teaching growth

A modern method of teaching that adapts to the Philippines' situation is a blended learning modality. Many countries do this kind of schooling, but this is still a recent development in the Philippines' education. As a result of this set-up, there is no vital planning in this particular era, mainly providing the robust framework for webinars and online engagement, especially for teacher interns (Malhotra \& Bhatia, 2021). Moreover, teacher interns would also like to recommend allowing them to attend training courses and webinars to understand further what they would do during the online teaching process (Ferdig et al., 2020). Via training courses and webinars, can find instructional methods that can suit the learners' level.

Significant response 1: "Since the situation does not permit us to have our face to face classes, as future teachers we can do some researches and watch seminars or webinars to help us on how are we going to deliver our lesson effectively and efficiently even without meeting the students personally".

Significant response 2: "Attend more online webinars that conducts about this new normal experience to gain more knowledge and to be equipped in this blended learning modality experience."

Significant response 3: "More trainings and experiences in online teaching." 
Theme 3: Stable internet connectivity

Technology is so vital in this period than before, particularly in learning. Several learning materials and techniques are found in internet collection. However, stable connectivity is an essential factor in enabling educators to do their required things, particularly in pandemics (Dwivedi et al., 2020); all are moving to the online world, most especially online teaching. Virtual education is a phenomenon in education today. Good internet access makes it easier to store and send files and, at the same time, provide swift information in the teaching-learning process (Morgan, 2020).

Significant response 1: "Poor Internet connection- must be improved."

Significant response 2: "For me over all only the internet connection has a big impact for all these strategies nowadays."

Significant response 3: "Stable Internet connection."

This research aimed to recognize the obstacles, coping strategies, and feedback of teacher interns during the outbreak of a pandemic in the blended learning modality. This research study centered on the blended learning modality experiences of elementary teacher interns in one of the laboratory Schools at Tacloban City. Researchers used semi-structured interviews and simulated focus group conversations to investigate teacher interns' comparative approach in the mixed learning modality. The study revealed ten themes were as follows; Unstable internet connectivity, Strenuous virtual classroom management, Virtual class distractions, Insufficient online teaching mastery, financial shortcomings (challenges), Strong personal disposition, reaching out for others (coping mechanisms), Easy tracking of students' online performance, Virtual teaching growth and Stable internet connectivity (suggestions).

According to the Reich et al. (2020), digital learning is now the latest standard in education. Experts must teach blended learning modalities to all in the academe, particularly future educators, to cope with the new normal of teaching. Getting an excellent intern personality and finding other advice help they resolve all the obstacles they have faced with these new teaching modalities. Though teacher interns experience internet loss, they still persevere in fulfilling their roles efficiently and effectively. Teacher interns find a way to overcome all the obstacles they face to perform their teaching activities considering the lack of online teaching experience (Asrifan, 2020). They are also capable of being imaginative and professional in this time of the pandemic.

\section{Conclusion}

Teacher interns' experiences and coping mechanisms help them identify their digital and class management skills. These could help the supervising teacher and the school heads plan and provide the necessary support for useful lessons using blended learning. The benefits are seen by providing training on online teaching techniques and digital literacy, particularly in specific subject fields. It needs administrators' prompt actions and support. The realization of teacher interns' improvement in teaching using blended learning modality is not just a mandated concept but also a part of the Philippine curriculum.

\section{References}

Agung, A. S. N., Surtikanti, M. W., \& Quinones, C. A. (2020). Students' Perception of Online Learning during COVID19 Pandemic: A Case Study on the English Students of STKIP Pamane Talino. SOSHUM: Jurnal Sosial Dan Humaniora, 10(2), 225-235.

Alayyar, G. M., Fisser, P., \& Voogt, J. (2012). Developing technological pedagogical content knowledge in pre-service science teachers: Support from blended learning. Australasian journal of educational technology, 28(8). 
Alimi, A. (2018). Lecturers' Awareness of, Access to and Competency in the Use of Google Apps for Education in Nigerian Universities (Doctoral dissertation, Educational Technology Department, Faculty of Education, University of Ilorin, Ilorin, Nigeria).

Alvis, L., Shook, N., \& Oosterhoff, B. (2020). Adolescents' prosocial experiences during the covid-19 pandemic: Associations with mental health and community attachments.

Asrifan, A. (2020). Pandemic, Humanity and Education.

Bailey, J. P., \& Schurz, J. (2020). COVID-19 Is Creating a School Personnel Crisis. American Enterprise Institute.

Baloran, E., \& Hernan, J. (2020). Crisis Self-Efficacy and Work Commitment of Education Workers among Public Schools during COVID-19 Pandemic.

Bartholomew, S. (2018). The antecedents of low-level classroom disruption: a bio-ecological perspective (Doctoral dissertation, Canterbury Christ Church University).

Bonk, C. J., Kim, M., \& Xu, S. (2016). Do you have a SOLE?: Research on informal and self-directed online learning environments. Learning, design, and technology: An international compendium of theory, research, practice and policy. Section: Informal resources and tools for self-directed online learning environments, 1-32.

Crawford, J., Butler-Henderson, K., Jurgen, R., Malkawi, B. H., Glowatz, M., Burton, R., Magni, P., \& Lam, S. (2020). COVID-19: 20 countries' higher education intra-period digital pedagogy responses. Journal of Applied Learning \& Teaching, 3. https://doi.org/10.37074/jalt.2020.3.1.

Cresswell, J. W., \& Plano Clark, V. L. (2011). Designing and conducting mixed method research. 2nd Sage. Thousand Oaks, CA, 201.

Davis, S. (2018). Juvenile programming activities in detention facilities: Self-adjustment and levels of stress (Doctoral dissertation, Lindenwood University).

De La Cruz, R. V. (2020). Exploring the Real-Life Experiences of Regular Teachers Handling Children with Autism in Inclusive Setting. The Educational Review, USA, 4(7), 135-149.

Dewey, J. (1986, September). Experience and education. In The educational forum (Vol. 50, No. 3, pp. 241-252). Taylor \& Francis Group.

Dhawan, S. (2020). Online Learning: A Panacea in the Time of COVID-19 Crisis. Journal of Educational Technology Systems. DOI: 10.1177

Dwivedi, Y. K., Hughes, D. L., Coombs, C., Constantiou, I., Duan, Y., Edwards, J. S., ... \& Upadhyay, N. (2020). Impact of COVID-19 pandemic on information management research and practice: Transforming education, work and life. International Journal of Information Management, 55, 102211.

Elibariki, N. (2014). The factors influencing shortage of teaching and learning resources in Tanzania primary schools (Doctoral dissertation, The Open University of Tanzania).

Ferdig, R. E., Baumgartner, E., Hartshorne, R., Kaplan-Rakowski, R., \& Mouza, C. (Eds.). (2020). Teaching, technology, and teacher education during the COVID-19 pandemic: Stories from the field. Association for the Advancement of Computing in Education.

Fernandez, A. A., \& Shaw, G. P. (2020). Academic leadership in a time of crisis: The coronavirus and COVID - 19. Journal of Leadership Studies, 14(1), 39-45.

Hill, J. R., \& Hannafin, M. J. (2001). Teaching and learning in digital environments: The resurgence of resource-based learning. Educational Technology Research and Development, 49(3), 37-52.

Jung, I., \& Latchem, C. (2011). A model for e - education: Extended teaching spaces and extended learning spaces. British Journal of Educational Technology, 42(1), 6-18. 
Kolb, D. A. (1984). The process of experiential learning. Experiential learning: experience as the source of learning and development. In : (pp. 20-38). Prentice-Hall, Inc..

Kothari, C. R. (2004). Research methodology: Methods and techniques. New Age International.

Malhotra, L., \& Bhatia, H. K. (2021). From walls to clouds: SWOCS of online learning from voices of prospective teacher educators in India in response to covid-19. The Online Journal of Distance Education and e-Learning, 9(1).

McAfee, M. (2018). Development and Validation of a Scale to Measure Misconceptions about Educational Psychology among Pre-service Teachers.

McCoy, B. R. (2016). Digital distractions in the classroom phase II: Student classroom use of digital devices for non-class related purposes.

Morgan, H. (2020). Best practices for implementing remote learning during a pandemic. The Clearing House: A Journal of Educational Strategies, Issues and Ideas, 93(3), 135-141.

Owston, R. D., Sinclair, M., \& Wideman, H. (2008). Blended learning for professional development: An evaluation of a program for middle school mathematics and science teachers. Teachers College Record, 110(5), 1033-1064.

Palloff, R. M., \& Pratt, K. (2013). Lessons from the virtual classroom: The realities of online teaching. John Wiley \& Sons.

Reich, J., Buttimer, C. J., Fang, A., Hillaire, G., Hirsch, K., Larke, L. R., ... \& Slama, R. (2020). Remote learning guidance from state education agencies during the covid-19 pandemic: A first look.

Rickwood, D., Deane, F. P., Wilson, C. J., \& Ciarrochi, J. (2005). Young people's help-seeking for mental health problems. Australian e-journal for the Advancement of Mental health, 4(3), 218-251.

Rufai, M. M., Alebiosu, S. O., \& Adeakin, O. A. S. (2015). A conceptual model for virtual classroom management. International Journal of Computer Science, Engineering and Information Technology, 5(1), 27-32.

Shosha, G. A. (2012). Employment of Colaizzi's strategy in descriptive phenomenology: A reflection of a researcher. European Scientific Journal, 8(27)

Toscano (2020) School Operations Following Covid-19: Challenges and Opportunities. Retrieved from https://www.blumshapiro.com/insights/school-operations-following-covid-19-challenges-and-opportunities/

Tsitsia, B. Y., Kabbah, S. K., Doyi, V., Kabe, S. K., \& Safo, P. (2020). Colleges of education student-teachers'perceptions on the e-learning in the era of covid-19 pandemic. European Journal of Education Studies, 7(12).

Tria, J. Z. (2020). The COVID-19 pandemic through the lens of education in the Philippines: The new normal. International Journal of Pedagogical Development and Lifelong Learning, 1(1), 2-4.

Vonderwell, S., \& Turner, S. (2005). Active learning and preservice teachers' experiences in an online course: A case study. Journal of technology and teacher education, 13(1), 65-84.

Westine, C., Oyarzun, B., Ahlgrim-Delzell, L., Casto, A., Okraski, C., Park, G., Person, J., \& ～～Steele, ～L. （2019). Familiarity, Current Use, and Interest in Universal Design for Learning Among Online University Instructors. International Review of Research in Open and Distributed Learning, 20(5), 15-41.

UNESCO (2020) Policy Brief: Education during COVID-19 and beyond. United Nations. 